\title{
Elaboration and Characterization of Nanostructured Biocements for Biomedical Applications
}

\author{
Nelson Heriberto Almeida Camargo*, Cristina Soares, Enori Gemelli \\ Programa de Pós-Graduação em Ciências e Engenharia de Materiais, \\ Universidade do Estado de Santa Catarina, Centro de Ciências Tecnológicas, \\ Campus Universitário, Bairro Bom Retiro, 89223-100 Joinville - SC, Brazil
}

Received: August 25, 2006; Revised: June 13, 2007

\begin{abstract}
Biocements formed from the composition $\mathrm{Ca} / \mathrm{P}$ have been studied and developed since 1983 . These biomaterials are promissing and have aroused great interest to biomedical surgery applications, fixation of prostheses and filling and reconstruction of bones. They can be employed as an element of load to fix implant and bone structure. In addition, biocements are easily shaped during surgical processes and favor early bone habitation, absorption, osseointegration, and osteoconduction of bone structure into the microstructure of the biocement thus favoring regeneration and reconstruction of bone tissue. This paper aims to develop biocements formed from calcium phosphate through the aqueous precipitation method by means of the dissolution-precipitation reaction, which involves solid/ liquid phase of $\mathrm{CaO}$ and phosphoric acid to form the calcium phosphate. The biocements investigated were synthesized when the molar ratios of $\mathrm{Ca} / \mathrm{P}=1.4,1.5,1.6,1.7$ and 1.8. The present results indicate that the aqueous precipitation method allowed nanostructured powder of calcium phosphate to form. Thermal treatment at $1300{ }^{\circ} \mathrm{C}$ for 2 hours provided biocements formed from calcium phosphate and hydroxyapatite. The study of hydration behaviour from 1 to 28 days in a solution, which contained $0.4 \%$ of sodium phosphate, emphasized phase modification and the presence of a microporous microstructure made of crystalline fibers. It was found that the shape and size of the crystalline fiber had a direct influence on the resulting mechanical properties. Investigating more carefully the behaviour of the specimens with a $\mathrm{Ca} / \mathrm{P}$ molar ratio of 1.5 , there was an increase in the strength value under compression as a function of time so that it reached the maximum value of strength $\pm 45 \mathrm{MPa}$ to specimens that had been hydrated for 28 days.
\end{abstract}

Keywords: elaboration, characterization, biocements, application, biomedical

\section{Introduction}

Nanostructured biocements formed from $\mathrm{Ca} / \mathrm{P}$, the calcium phosphates, are promising, that is, they might be applied to maxillofacial surgery, implant fixation, and they might also be used as a matrix to repair, reconstruct bone tissue and eliminate defects. This is possible due to the fact that this biomaterial is capable of shaping and hardening when mixed with water. In contact with water, calcium phosphates react forming stable hydrated crystalline composites through a reaction of exothermic hydration yielding microporous ceramic mass ${ }^{1,2}$. Such material also presents good biocompatibility and its mineral characteristics are similar to the ones of the bone structure of the human skeleton, which suggests that it is promising, if applied to orthopedics and dentistry, implant fixation and regeneration of bone tissue $\mathrm{e}^{3-5}$.

Nanostructured biocements as calcium phosphates present a surface whose area is large, thus favoring malleability, hydration, which speeds the time of hardening the biomaterial. When biologically applied, they present early biodegradation, bioresobable by bone structure, beginning of formation of a new bone tissue approximately from 30 to 60 minutes after being in contact with body fluid ${ }^{4,6,7}$.

Different compositions of biocements are synthesized from mixtures of calcium phosphate powder in an aqueous environment. After being synthesized, these compositions present a spontaneous capacity to harden at room temperature or body temperature so that one or more constituents of the mixture will dissolve and one or more crystal composites will precipitate and might form four kinds of calcium phosphate cement, namely, "brushite", hydroxyapatite, hydroxyapatite poor in calcium and amorphous calcium phosphate. Among them, hydroxyapatite poor in calcium is the one, which is the most similar to the structure of bone mineral.

The aim of this paper is to optimize the method for synthesizing the nanostructured calcium phosphate powder and its characterization, that is, mineral, morphological characterization and characterization of hydration behaviour, mechanical properties and microstructure of biocements.

\section{Materials and Methods}

In order to synthesized different compositions of nanostructured calcium phosphate, calcium carbonate $\left(\mathrm{CaCO}_{3}\right)$ was used, it was provided by the LABSYNTH LTDA laboratory, $98 \%$, serial number 24996, and phosphorus oxide powder $\left(\mathrm{P}_{2} \mathrm{O}_{5}\right)$, provided by RIEDEL-DE HAËN laboratory from Germany, $99.5 \%$, serial number 1807. Different compositions of calcium phosphate were synthesized according to the following molar ratios: $\mathrm{Ca} / \mathrm{P}=1.4,1.5,1.6,1.7$ and 1.8 . Inicially, the calcination of $\mathrm{CaCO}_{3}$ powder took place in a furnace at $900{ }^{\circ} \mathrm{C}$ for 2 hours, the aim was to eliminate carbon from the calcium oxide $(\mathrm{CaO})$. The specimens were prepared by means of the aqueous precipitation method, which is based on a dissolution-precipitation reaction. Such method involved a solid/liquid phase of $\mathrm{CaO}$ and the phosphoric acid needed to form compositions with different $\mathrm{Ca} / \mathrm{P}$ molar ratios. During the synthesis, all the compositions had their $\mathrm{pH}$ value monitored approximately every 20 minutes as shown in Figure 1, the colloidal 
solution had been kept under mechanical agitation for 24 hours. Afterwards, the colloidal solution was poured into a pear recipient in order to eliminate the solvent. The recipient was fixed to a rotating evaporator and it had gone through rotation at $8 \mathrm{rpm}$ parcially submerged in a silicone oil bath at $70{ }^{\circ} \mathrm{C}$. The ceramic powder recovered from the recipient turned out to be white and the humidity was about $7 \%$. The material recovered from the recipient went through a process of grinding and sieving with mesh $140 \mu \mathrm{m}$. The powder recovered from grinding and sieving underwent thermal treatment at $1300{ }^{\circ} \mathrm{C}$ for 2 hours in order to produce the biocements. The studies on morphological and mineral characterization were conducted through a Scanning Electron Microscope, namely ZEISS DSM 940A, $30 \mathrm{Kv}$ by means of a system of secondary electron (SE) and an X ray Diffractometer, namely Shimadzu X ray Diffractometer Lab X XRD-6000, with a copper anticathode; the parameter was the diffraction angle $2 \theta$ with goniometric dislocation of $2 \% \mathrm{~min}$. The specimens were prepared for observation in the scanning electron microscope and the microanalysis through EDX. Preparation was done through a sample holder and a carbon double-sided tape, that is, the carbon double-sided tape was attached under the flat surface of the sample holder, then the ceramic powder, the biocement powder and the fragments of the specimens recovered from the mechanical tests were fixed under the surface of the carbon tape. All of the specimens were covered with metallic films through an sputter coater, namely Bal-Tec model SCD 050 Sputter Coater. The parameters of ionic deposition were set up as follows: temperature in the camera of metallization at $20^{\circ} \mathrm{C}$, the current was $40 \mathrm{~mA}$, the stress was $2 \mathrm{kV}$ and time of deposition, 120 seconds.

The hydration tests were conducted on 10 specimens for each composition in cylindrical shape, with dimensions of $6 \mathrm{~m} \times 12 \mathrm{~mm}$. These tests were conducted from a solution, which contained $0.4 \%$ of Sodium Phosphate $\left(\mathrm{Na}_{2} \mathrm{HPO}_{4}\right)$ at room temperature $\left(25^{\circ} \mathrm{C}\right)$. The hydration times were $1,2,3,7$ and 28 days. After hydration, the specimens underwent mechanical tests under compression. A machine of universal test, namely EMIC comprising a cell for load measure whose capacity was $1.000 \mathrm{KN}$ was used. The tests were conducted according to regulation E9-89a ASTM. Afterwards, the material recovered from the mechanical test was prepared carefully for the characterization studies, which employed the techniques of scanning electron microscopy and $\mathrm{X}$ ray diffractometry

\section{Results and Discussion}

Inicially, results from the $\mathrm{pH}$ monitoring of the colloidal solutions indicate an increase in $\mathrm{pH}$ value for the dissolution of the $\mathrm{CaO}$ in

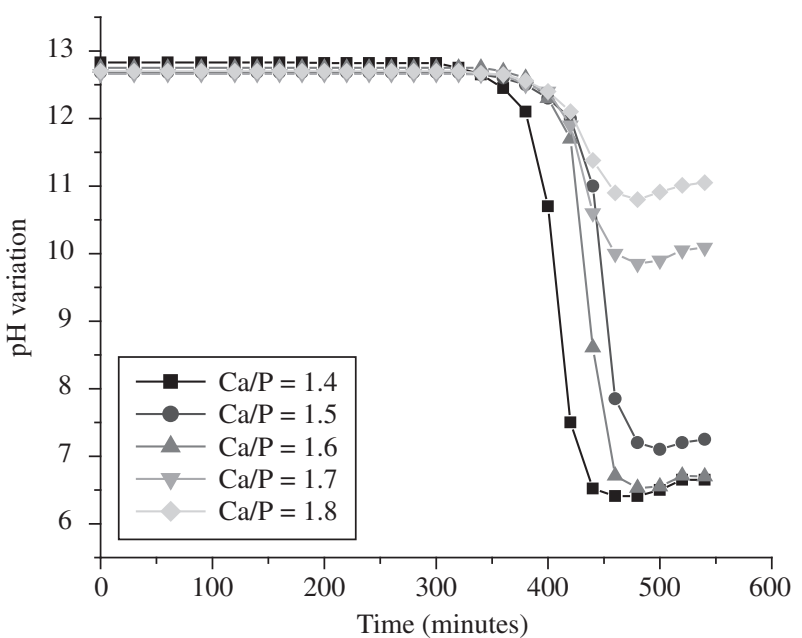

Figure 1. The curves of $\mathrm{pH}$ measures of colloidal solutions as a function of time. aqueous solution, increasing from 7 to 12.7 . In addition, there was a slow decrease in this value for the different compositions as the phosphoric acid solution was added to the colloidal solution drop by drop. Results point to a difference in the final $\mathrm{pH}$ value among the compositions after 24 hours of mechanical agitation (Figure 1). This can be explained by the stronger presence of $\mathrm{CaO}$ in the compositions. When the $\mathrm{Ca} / \mathrm{P}$ molar ratios $=1.7$ and 1.8 , there was a formation of a larger amount of bonding with hydrogen, generating $\mathrm{OH}^{-}$ions.

Studies on morphological characterization through the technique of electron microscopy using the system of secondary electrons (SE), for all the specimens of calcium phosphate powders when the molar ratios of $\mathrm{Ca} / \mathrm{P}=1.4,1.5,1.6,1.7$ and 1.8. It was observed, for all the compositions, a morphology, which consisted of agglomerates of thin particles of nanometric magnitude $(\mathrm{d}<100 \mathrm{~nm})$, as shown in Figure 2.

$\mathrm{X}$ ray diffractometry analysis of the powder recovered from drying in the rotating evaporador indicate that with a $\mathrm{Ca} / \mathrm{P}$ molar ratio $=1.4$, it was possible to observe the presence of semi-amorphous hydrated calcium phosphate (brushite) in $\mathrm{CaHPO}_{4} \cdot 2 \mathrm{H}_{2} \mathrm{O}$ (JCPDS no. 01-0395) and calcium carbonate (JCPDS no. 47-1743), as shown in Figure 3. When the molar ratio of $\mathrm{Ca} / \mathrm{P}=1.5$, semi-amorphous hydrated calcium phosphate and calcium carbonate were found in $\mathrm{Ca}_{3}\left(\mathrm{PO}_{4}\right)_{2} \cdot \mathrm{H}_{2} \mathrm{O}$ (JCPDS no. 18-0303), as seen in the $\mathrm{X}$ ray spectrum (Figure 3 ). The presence of the calcium carbonate phase in these compositions can be explained by the time of calcination of calcium carbonate at $900{ }^{\circ} \mathrm{C}$ for 2 hours.

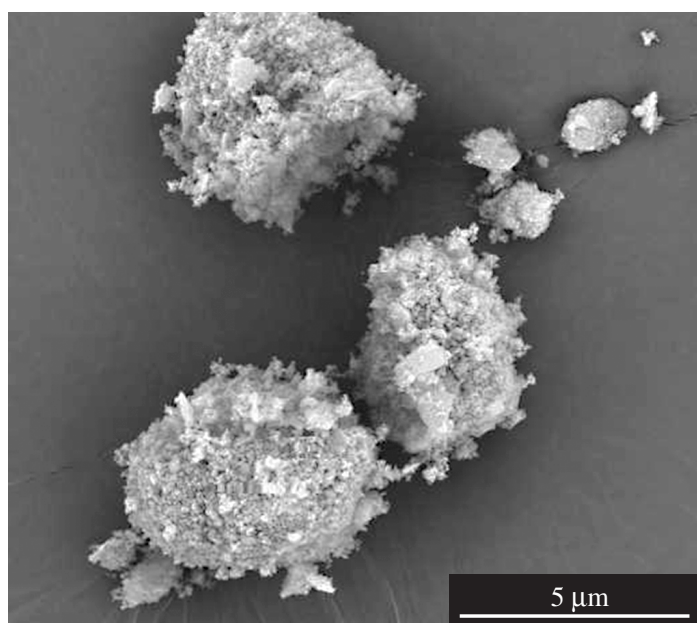

(a)

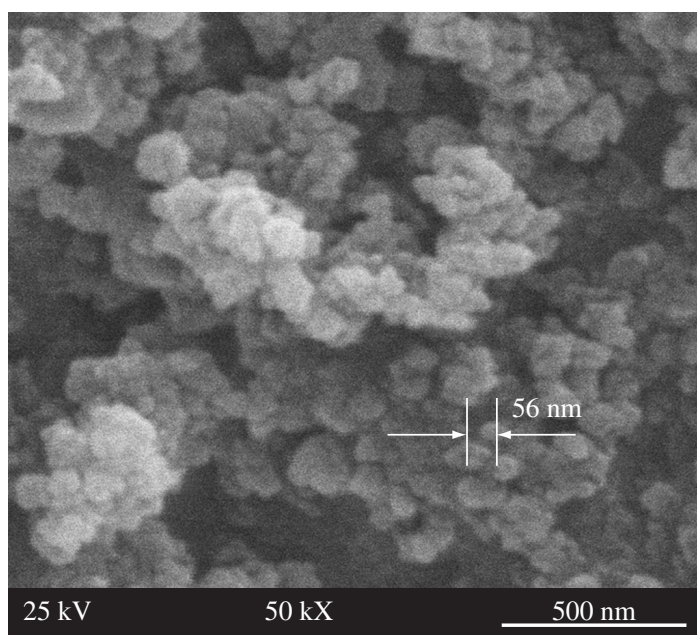

(b)

Figure 2. Morphology of calcium phosphate powder resulting from the rotating evaporator, when the ratio of $\mathrm{Ca} / \mathrm{P}=1.5$. 


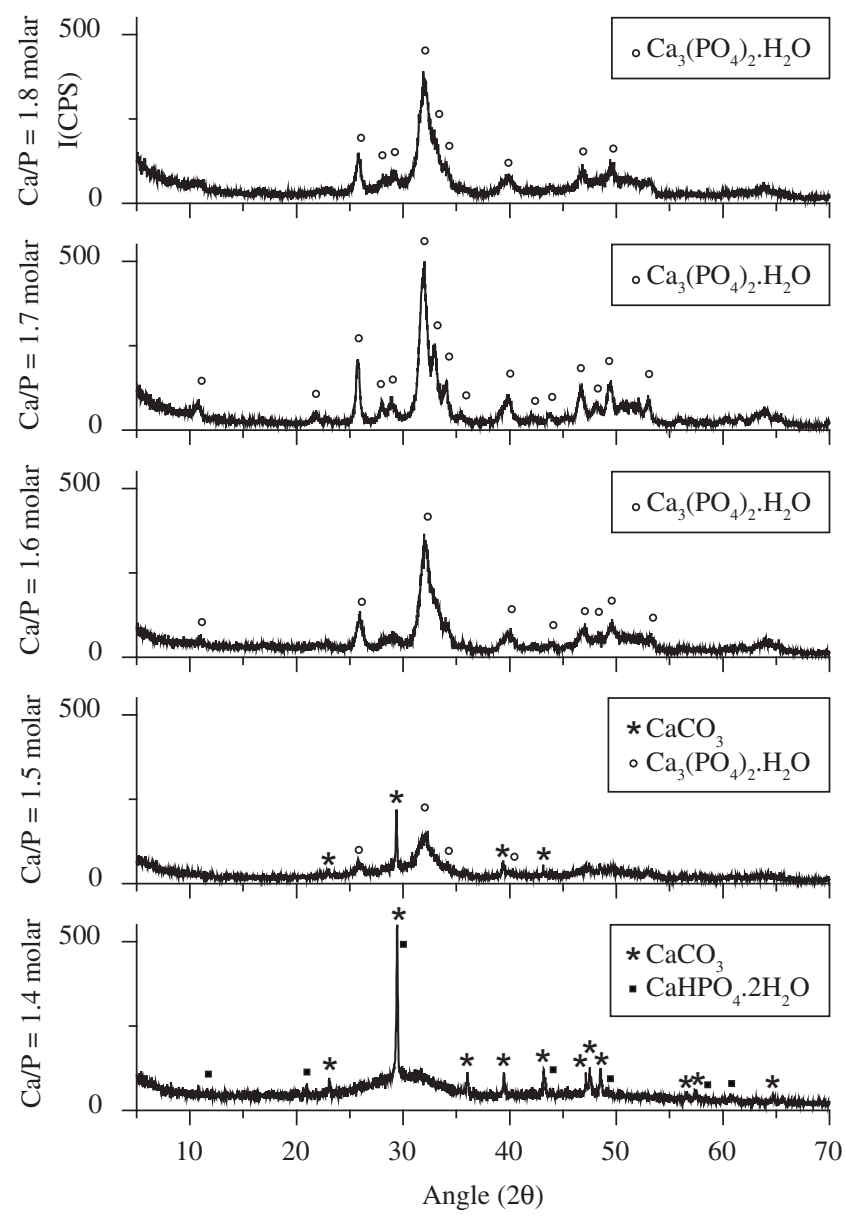

Figure 3. Spectra of $\mathrm{X}$ ray diffractometry on powders recovered from drying in rotating evaporator for the different compositions (peaks per second as a function of $2 \theta$ )

This was not enough to eliminate carbon completely, so the presence of calcium carbonate phase was detected in the $\mathrm{X}$ ray spectra of the compositions. As for the compositions formed when the molar ratios of $\mathrm{Ca} / \mathrm{P}=1.6,1.7$ and 1.8, semi-amorphous hydrated calcium phosphate was found in $\mathrm{Ca}_{3}\left(\mathrm{PO}_{4}\right)_{2} \cdot \mathrm{H}_{2} \mathrm{O}$, as the spectra in Figure 3 shows, this has already been found in the compositions 1.4 and $1.5 \mathrm{M}$.

$\mathrm{X}$ ray diffractometry was used to examine the biocement powders obtained from thermal treatment at $1300{ }^{\circ} \mathrm{C}$ for 2 hours. Results from the diffractometry revealed in their spectra (Figure 4) the presence of calcium phosphate phase in $\mathrm{Ca}_{3}\left(\mathrm{PO}_{4}\right)_{2}$ (JCPDS no. 09-0169), presenting the main plan of diffraction [021] and calcium oxide $(\mathrm{CaO})$ for the compositions synthesized when the molar ratios of $\mathrm{Ca} / \mathrm{P}=1.4$ and 1.5. With $\mathrm{Ca} / \mathrm{P}$ molar ratios $=1.6$ and 1.7 , hydroxyapatite phase was present in $\mathrm{Ca}_{9} \mathrm{HPO}_{4}\left(\mathrm{PO}_{4}\right)_{6}(\mathrm{OH})_{2}$ (JCPDS no. 46-0905), with main plan of diffraction [211], as shown in the spectra in Figure 4. When the molar ratio of $\mathrm{Ca} / \mathrm{P}=1.8$, hydroxyapatite phase was present in its spectra in the composition $\mathrm{Ca}_{10}\left(\mathrm{PO}_{4}\right)_{6}(\mathrm{OH})_{2}$ (JCPDS no. 74-0565), with main plan of diffraction [211].

The specimens used for the hydration studies were moulded in cylindrical shape with dimensions of $6 \mathrm{~m} \times 12 \mathrm{~mm}$. After being hydrated for 24, 48, 72 hours, 7 and 28 days, the specimens were taken away from the recipient containing the solution of sodium phosphate at $4 \%$ and underwent a compression test. Afterwards, the strength for the different biocement compositions as function of the time of hydration was determined. Results from the compression tests were shown in Figure 5. Findings indicate that the values of strength under compression were kept lower than the other compositions when

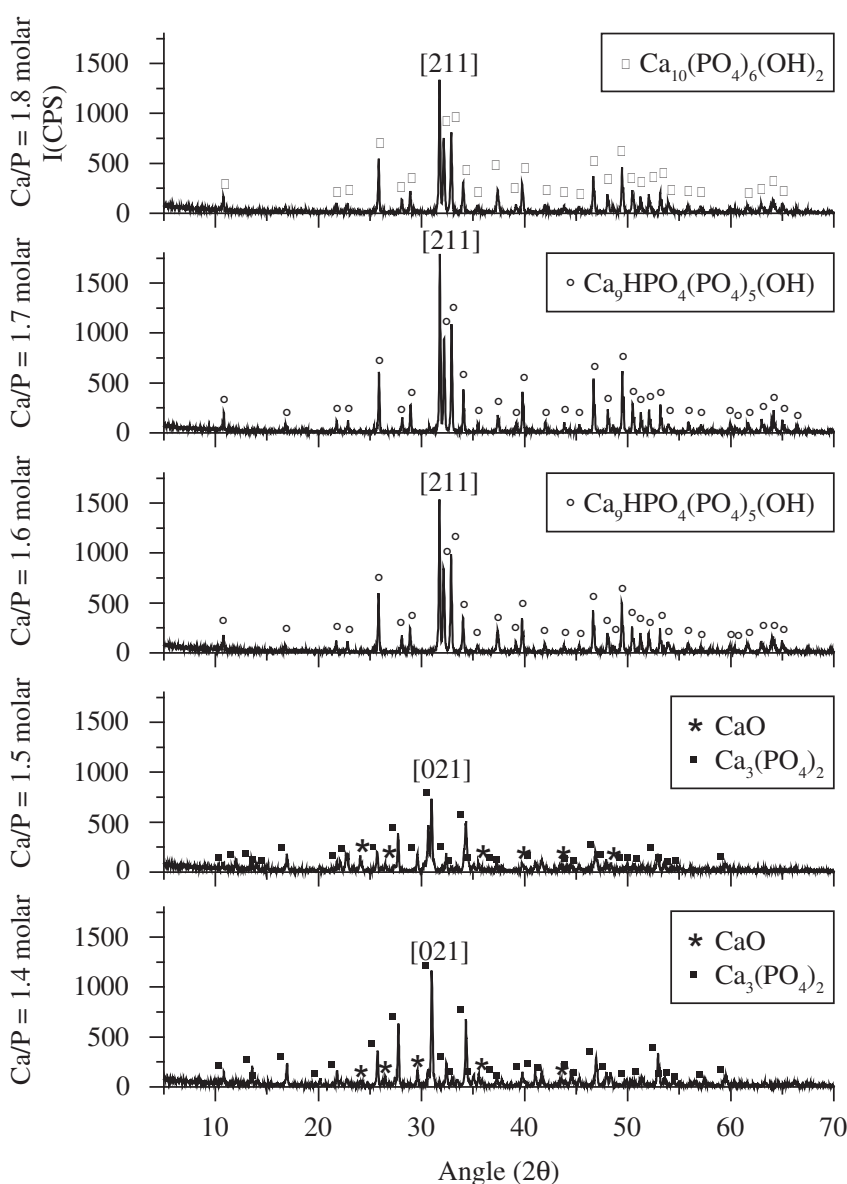

Figure 4. Spectra of $\mathrm{X}$ ray diffractometry on the biocement powders resulting from the heat treatment at $1300{ }^{\circ} \mathrm{C}$ for 2 hours for the different compositions (peaks per second as a function of $2 \theta$ ).

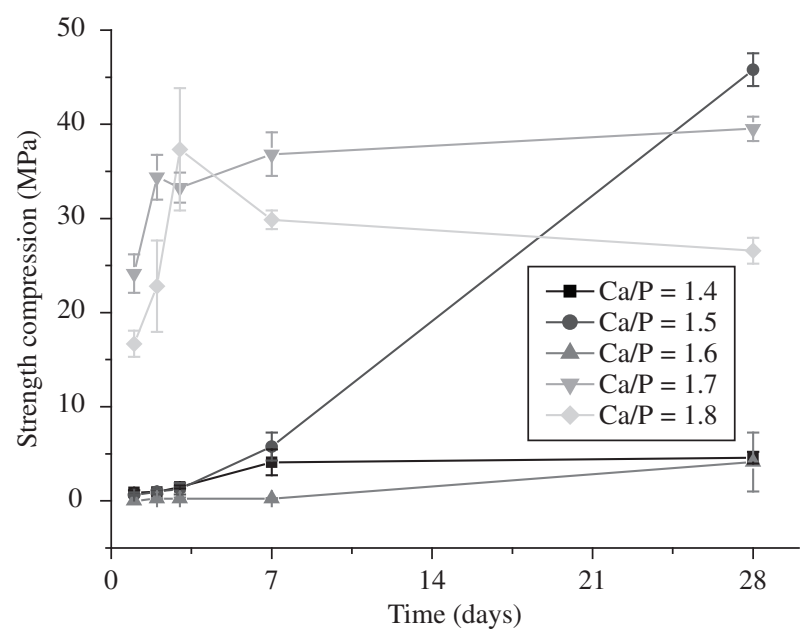

Figure 5. Measures of strength under compression of hydrated specimens as function of time as days.

the molar ratios of $\mathrm{Ca} / \mathrm{P}=1.4$ and 1.6 . With a $\mathrm{Ca} / \mathrm{P}$ ratio $=1.5$, an increasing value of strength was found as a function of the time of hydration so that it was possible to observe a better result of the strength $(\sigma \mathrm{R}=45 \mathrm{MPa})$ for the time of 28 days. Results revealed that there is a difference in the hydration form and crystalline phase formation to the different compositions, as it has already been shown in the $\mathrm{X}$ ray spectra. It was found that there is a better hydration and 
formation of crystalline nanostructure for the compositions with a $\mathrm{Ca} / \mathrm{P}$ molar ratio $=1.4$ (Figures 6a, b) and 1.5 (Figures 7a, 7b). Another finding was the modification in the shape of the microstructure and the crystalline nanostructure as a function of the time of hydration, as it can be seen in the Figures $8 \mathrm{a}, \mathrm{b}$, after 7 days of hydration. This can be explained by the presence of the microporous microstructure formed by fine homogeneous fibers (Figures $7 \mathrm{a}, \mathrm{b}$ ) of calcium phosphate and hydroxyapatite, as it has already been shown in the $\mathrm{X}$ ray spectra (Figures 9 and 10). When the molar ratios of $\mathrm{Ca} / \mathrm{P}=1.7$ and 1.8, there was an improvement in the results of strength for the first days of hydration if compared to the other compositions. It was possible to note better values $(\sigma \mathrm{R}=39 \mathrm{MPa})$ for the composition with a $\mathrm{Ca} / \mathrm{P}$ molar ratio $=1.7$, as shown in Figure 5. Results from the strength under compression indicate that the values found in the compositions $1.5,1.7$ and $1.8 \mathrm{M}$ are superior to the values found in the bibliography, but it is noteworthy that those studies have employed different methods for synthesis and similar hydration processes ${ }^{11,12}$. If one compares these results to the materials used to obtain polymeric bonding, for instance $\mathrm{PMMA}^{13}$, those results are slightly inferior to the present ones. This indicates that nanostructured biocements favor the hydration and hardening as a function of hydration time, which may lead to improve even more the values of properties.

The hydration studies for the different compositions of biocements were conducted as a function of the following timetable 1, 2, 3, 7 and 28 days. Scanning electron microscopic observations were performed on the fracture surface of the specimens recovered from mechanical tests. Results indicate a surface modification of the biocement particle morphology in a solution containing sodium phosphate at $4 \%\left(\mathrm{Na}_{2} \mathrm{HPO}_{4}\right)$, it was possible to notice a gel formation on the particle surface, the growth of a crystalline nanostructure in the form of fibers and the formation of microporous microstructure for the different compositions.

The study of microstructure and nanostructure characterization for the different compositions revealed the modification of the microstructure and nanostructure as a function of the time of hydration, and formation of new phases revealed by the technique of $\mathrm{X}$ ray diffractometry.

XRD diffractometry was performed on the specimens recovered from the hydration for the different biocement compositions. The

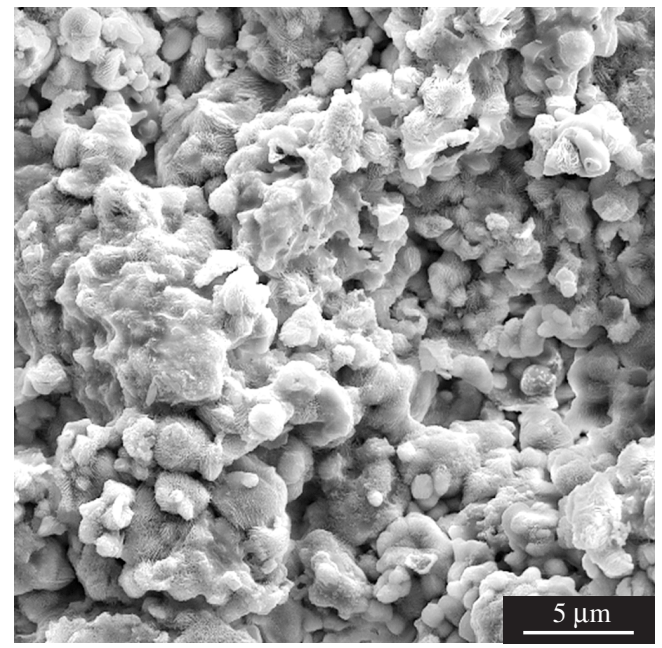

(a)

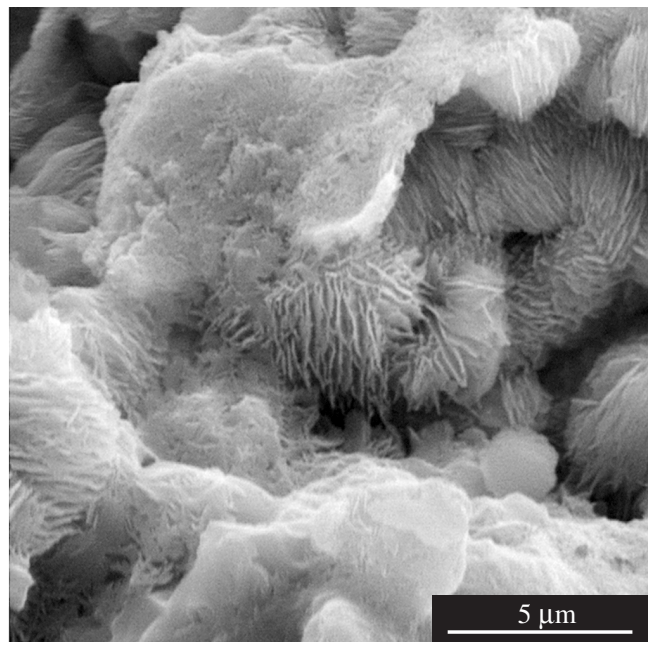

(b)

Figure 6. a) Intergranular fracture and microporosity; and b) nanometric crystalline fiber, gel formation and microporosity when the molar ratio of $\mathrm{Ca} / \mathrm{P}=1.4$ for 1 day of hydration.

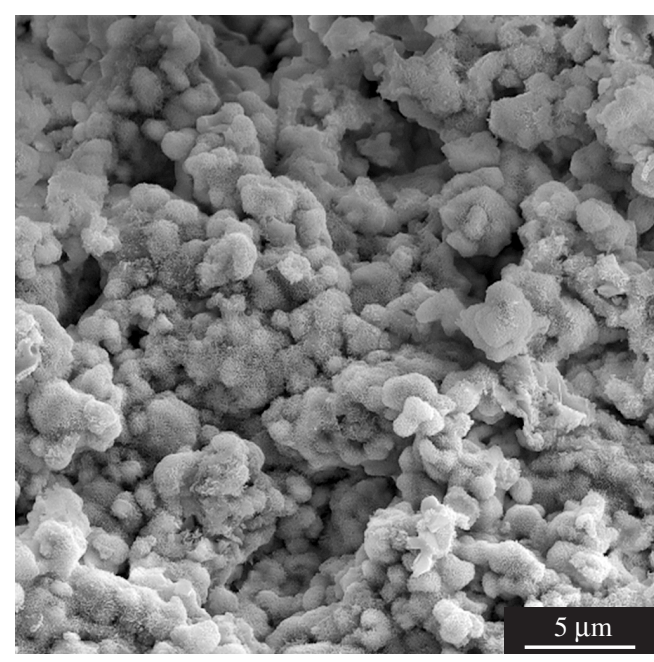

(a)

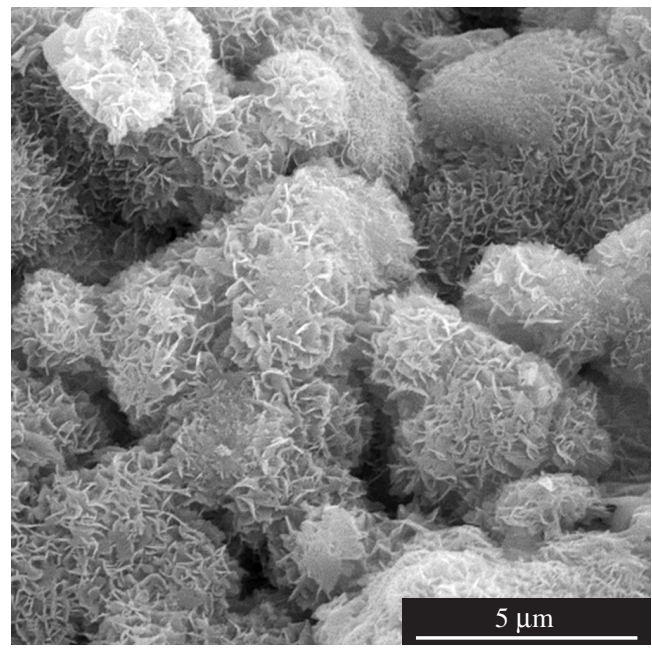

(b)

Figure 7. a) Intergranular fracture and microporosity; and b) nanometric crystalline fiber and microporosity when the molar ratio of $\mathrm{Ca} / \mathrm{P}=1.5$ for $1 \mathrm{day}$ of hydration. 


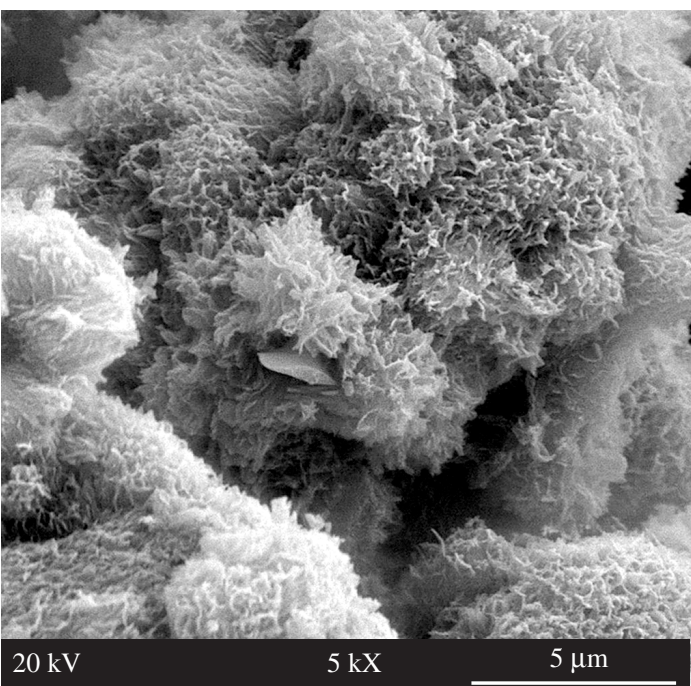

(a)

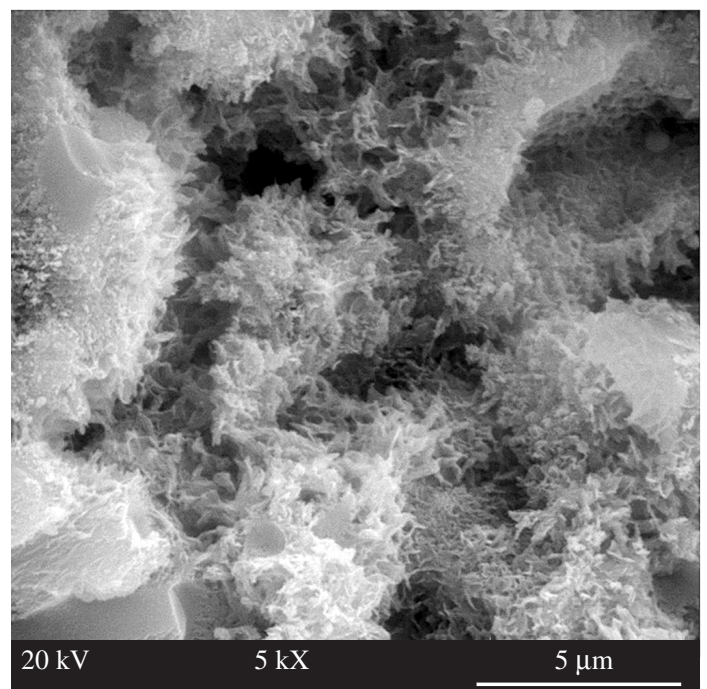

(b)

Figure 8. a) Microporosity and crystalline fiber when the molar ratio of $\mathrm{Ca} / \mathrm{P}=1.4$ for 7 days of hydration; and b) shows microporosity and nanometric crystalline fiber when the molar ratio of $\mathrm{Ca} / \mathrm{P}=1.5$ for 7 days of hydration.

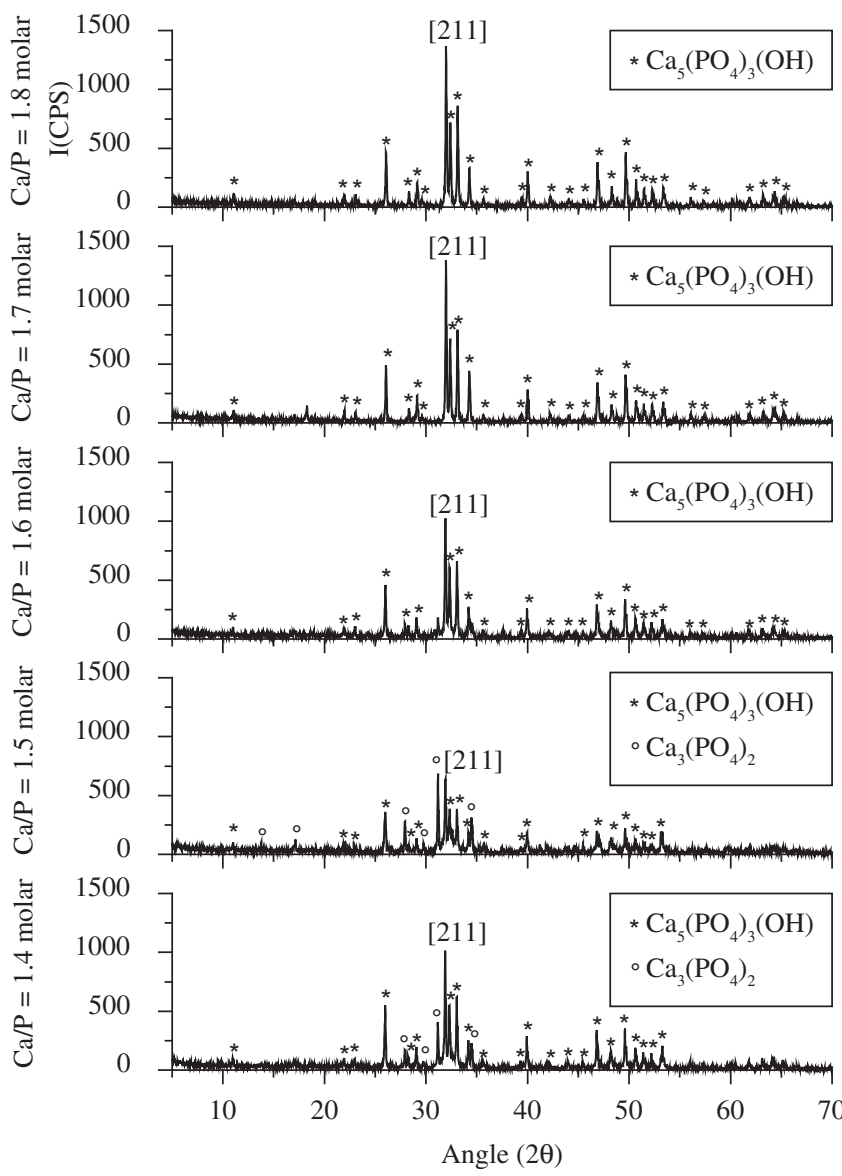

Figure 9. Spectra of $\mathrm{X}$ ray diffractometry on specimens which had been hydrated for one day for the different compositions (peaks per second as a function of $2 \theta$ ).

characterization results reveal in their spectra a modification of phases so that it was possible to notice the presence of hydroxyapatite phase in $\mathrm{Ca}_{5}\left(\mathrm{PO}_{4}\right)_{3} \mathrm{OH}$ in the hexagonal structure with main plan of diffrac-

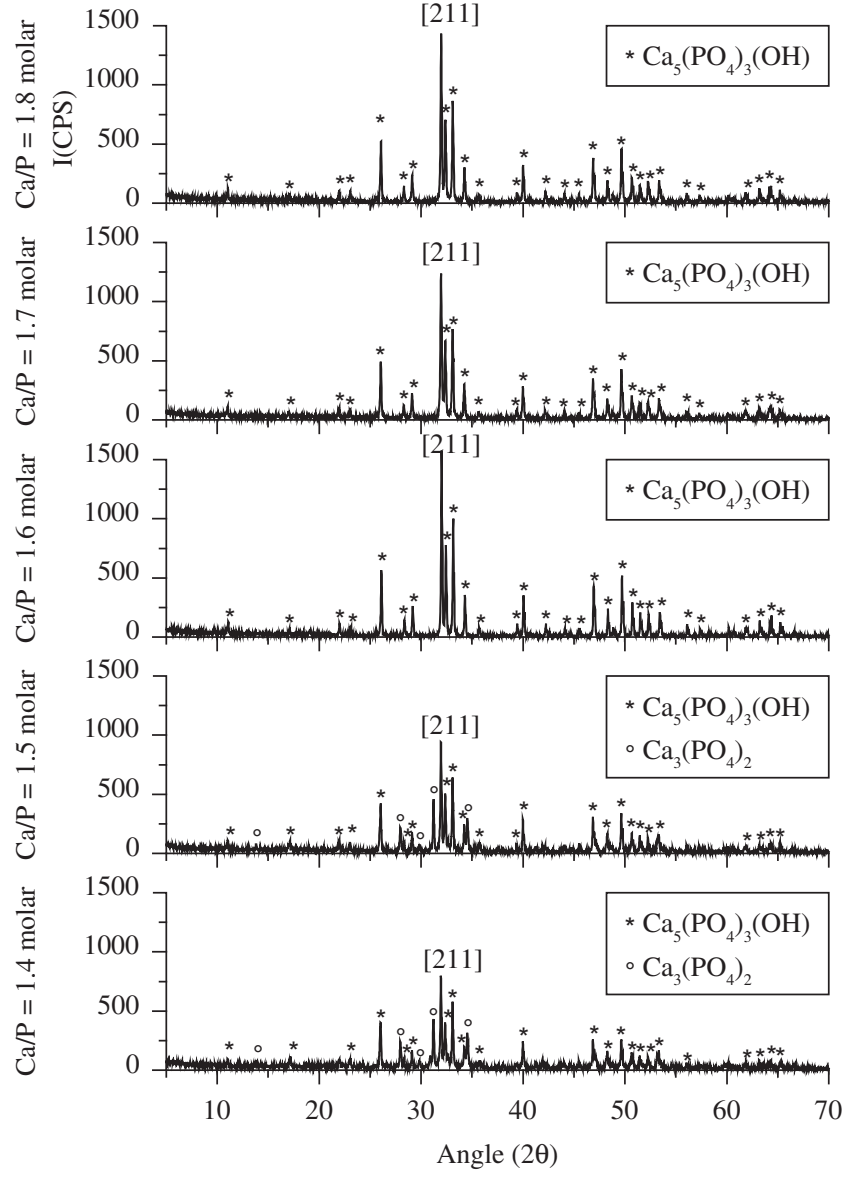

Figure 10. Spectra of $X$ ray diffractometry on specimens, which had been hydrated for 28 days for the different compositions (peaks per second as a function of $2 \theta$ ).

tion [211] for the angle $\theta=31.9$ for all of the compositions and times of hydration, as it can be seen in Figure 9. It was also found that for the compositions with $\mathrm{Ca} / \mathrm{P}$ molar ratios $=1.4$ and 1.5 , the presence 
of the calcium phosphate phase (Whitlockite) in the composition $\mathrm{Ca}_{3}\left(\mathrm{PO}_{4}\right)_{2}$, for the angle $\theta=31.2$, as it can be observed in the XRD spectra in Figure 10.

\section{Conclusion}

Calcium phosphate nanostructured biocements are considered promising for biomedical applications, orthopedics, traumatology and orthodontics. As for orthopedics, they might be used as a matrix to regenerate and rebuild bone tissue through preventive medicine; as for traumatology, to recover and rebuild parts of damaged and/or lost bone tissue; as for orthodontics, to treat decay, to put in and cement fillings, and to rebuild bones.

The present results emphasize the finding that the aqueous precipitation method allows the formation of powders which consist of agglomerates of nanometric particles of calcium phosphate as semi-amorphous brushite phase for the different compositions, as it is shown in Figure 2a,b.

$\mathrm{X}$ ray diffractometry studies emphasize the presence of the brushite phase for the powders resulting from drying in rotative evaporador. The presence of calcium carbonate in the compositions when the molar ratios of $\mathrm{Ca} / \mathrm{P}=1.4$ and 1.5 is explained by the length of time of calcination of $\mathrm{CaCO}_{3}$. Two hours time was not enough.

The biocements resulting from the thermal treatment at $1300{ }^{\circ} \mathrm{C}$ for 2 hours are formed basically by calcium phosphate phase and hydroxyapatite, as it can be seen in the $\mathrm{X}$ ray spectra shown in Figure 4 . The presence of calcium oxide in the compositions 1.4 and 1.5 is related to the presence of calcium carbonate, which was already existing in these compositions.

The mechanical tests put emphasis on the values of mechanical properties for the different compositions. It is possible to note stabler values as a function of the time of hydration when the molar ratio of $\mathrm{Ca} / \mathrm{P}=1.7$. With a $\mathrm{Ca} / \mathrm{P}$ molar ratio $=1.5$, it was found an increase in the value of strength as a function of the time of hydration, that is, a better result of strength (45 MPa) was presented for 28 days of hydration. This value is superior to the values found in the bibliography.

The characterization results from the $\mathrm{X}$ ray diffractometry on the hydrated specimens show clearly the modification of phase for the different compositions, resulting in the hydroxyapatite phase in $\mathrm{Ca}_{5}\left(\mathrm{PO}_{4}\right)_{3} \mathrm{OH}$ for all of compositions and all hydration times. Another finding was the presence of calcium phosphate phase in $\mathrm{Ca}_{3}\left(\mathrm{PO}_{4}\right)_{2}$ when the molar ratios $\mathrm{Ca} / \mathrm{P}=1.4$ and 1.5 , as shown in the spectra in Figures 9 and 10. Such phases favour the reabsorption and the rebuilding of the bone tissue.

The hydration studies focus on phase modification, formation of gel and microporous microstructure. Investigating more carefully the formation of the crystalline nanostructure when the $\mathrm{Ca} / \mathrm{P}$ molar ratios $=1.4($ Figure $6 \mathrm{a}, \mathrm{b})$ and $1.5($ Figure $7 \mathrm{a}, \mathrm{b})$, there is another finding, that is, the growth of the crystalline nanostructure as function of the time of hydration, which might have possibly contributed to the values of mechanical properties for some compositions.

\section{References}

1. Baïlon JP, Dorolt JM. Des matériaux, École Polytechnique de Montréal; 2000. p. 736.

2. Changsheng L, Huifang S, Feiyue C, Haiyan, Z. Rheological properties of concentrated aqueous injectable calcium phosphate cement slurry. Biomaterials. 2006; 27(29):5003-5013.

3. Kumta PN, Sfeir C, Lee DH, Olton D, Choi D. Nanostructured calcium phosphates for biomedical applications: novel synthesis and characterization. Acta Biomaterialia. 2005; 1(1):65-83.

4. Yuasa T, Miyamoto Y, Ishikawa K, Takechi M, Momota Y, Tatehara S, Nagayama M. Effects of apatite cements on proliferation and differentiation of human osteoblasts in vitro. Biomaterials. 2004; 25(7-8):1159-1166.

5. Liu H, Shao H, Chen F, Zheng H. Effects of the granularity of raw materials on the hydration and hardening process of calcium phosphate cement. Biomaterials. 2003; 24(23):4103-4113.

6. Wang X, Ma J, Wang Y, He B. Structural characterization of phosphorylated chitosan and their applications as effective additives of calcium phosfate cements. Biomaterials. 2001; 22(16):2247-2255.

7. Fernandéz E, Ginebra MP, Boltong MG, Driessens FCM, Ginebra J, De Maeyer EAP, Verbeeck RMH, Planell JA. Kinetic study of the setting reaction of a calcium phosphate bone cement. Journal of Biomedical Materials Research. 1996; 32(3):367-374.

8. Oreffo ROC, Driessens FCM, Planell JA, Triffitt JT. Growth and differentiation of human bone marrow osteoprogenitor on novel calciun phosphate cements. Biomaterials. 1998; 19(20):1845-1854.

9. Nurit J, Margerit J, Terol A, Boudeville P. pH-metric study of the setting reaction of monocalcium phosphate monohydrate/calcium oxide-based cements. Journal of Materials Science: Materials in Medicine. 2002; 13(11):1007-1014.

10. Camargo NHA, Soares C, Gemelli, E. Síntese e caracterização de biocimentos nanoestruturados para aplicações cirúrgicas ortopédicasodontológicas. $50^{\circ}$ Congresso Brasileiro de Cerãmica, 22 a 25 Maio, Blumenau-SC., p. 1-14; 2006.

11. Yamamoto H, Niwa S, Hori M, Hattori T, Sawai K, Aoki S, Hirano M, Takeuchi, H. Mechanical strength of calcium phosphate cement in vivo and vitro. Biomaterials. 1998; 19(17):1587-1591.

12. Khairoun I, Driessens FCM, Boltong MG, Planell JA, Wenz, R. Addition of cohesion promoters to calcium phosphate cements. Biomaterials. 1999; 20(4):393-398.

13. Goto K, Tamura J, Shinzato S, Fujibayashi S, Hashimoto M, Kawashita, M, Kokubo T, Nakamura T. Bioactive bone cements containing nanosized titania particles for use as bone substitutes. Biomaterials. 2005; 26(33):6496-6505. 